\title{
The Empirical Study on the Application-oriented University Quality Culture Construction Performance in the Post Massification Stage -A Case of Zhejiang Province
}

\author{
Fei $\mathrm{GAO}^{1}$ a
}

\author{
${ }^{1}$ The Non-governmental Higher Education Institute of China, Zhejiang Shuren University; \\ Hangzhou, Zhejiang Province, China \\ agaofeibd@163.com
}

\begin{abstract}
Keywords: Post massification, Application-oriented universities, Quality culture.
\end{abstract}
\begin{abstract}
As higher education has stepped into post massification stage, application-oriented universities have more and more payed attention to improve quality and pursuit excellence. The quality culture emphasises both faith and technique, is an important indicator and criterion for measuring educational level. The Regression analysis of 179 samples has shown that: quality data construction, stakeholder participation, quality strategy management and quality evaluation mechanism, have significant role in promoting application-oriented universities to cultivate high-level practical talents, engage in technological innovation and practical research, and serve regional social-economic development.
\end{abstract}

\section{Introduction}

Higher Education Quality Report published in 2016 points that the gross enrollment ratio of higher education in China has reached $40 \%$.( Wei ZHANG., 2016) While after the massification and before the popularization, higher education often experienced the post massification Stage, a period of fluctuation and pause. application-oriented universities differ from research universities and vocational colleges. application-oriented universities more emphasize undergraduate teaching, mainly provide undergraduate education, and pay close attention to service industry development. Such universities are facing serious challenges in post massification stage: distinctive features, talent training problems and lower transferring rate. Quality culture could provide the breakthrough for university reform. Quality culture includes all spiritual activity, mental behavior and spiritual and physical products about the quality.( Mao-Xun HE,2004) It contains both quality management technocratic element and quality commitment cultural element.( European University Association,2005) The quality culture construction should become an Important thinking and way in application-oriented university development. Many provinces in China are identifying pilot application-oriented universities. The study will conduct an investigation based on Zhejiang to explore application-oriented university quality culture construction.

\section{Basic Situation of Application-oriented University Quality Culture Construction Performance}

Application-oriented university devotes itself to train applied talents with professional accomplishment, comprehensive practical ability and creative spirit, attaches importance to the use, promotion and transformation of knowledge into practical work, and emphasizes on serving the regional community and local development. Teachers from 6 application-oriented universities in Zhejiang are selected as samples, 179 valid questionnaires are received. There are 4 public universities and 2 private universities. The sample is as follows. Table1 Shows the sample basic information. Respondents include Full-time teachers, administrative staffs, college or department heads, and university level managers. 
Table 1 Sample Basic Information

\begin{tabular}{|c|c|c|c|}
\hline \multicolumn{2}{|l|}{ Basic information } & $\mathrm{N}$ & Percentage \\
\hline \multirow{5}{*}{ Subject attribution } & Humanities & 25 & $14.0 \%$ \\
\hline & Social sciences & 64 & $35.8 \%$ \\
\hline & Engineering & 63 & $35.2 \%$ \\
\hline & Science & 26 & $14.5 \%$ \\
\hline & Others & 1 & $0.6 \%$ \\
\hline \multirow{5}{*}{ Working life } & Less than 5 years & 43 & $24.0 \%$ \\
\hline & 5-10 years & 64 & $35.8 \%$ \\
\hline & $11-20$ years & 58 & $32.4 \%$ \\
\hline & $21-30$ years & 13 & $7.3 \%$ \\
\hline & More than 30 years & 1 & $0.6 \%$ \\
\hline \multirow{5}{*}{ Professional title } & Assistant & 23 & $12.8 \%$ \\
\hline & Lecturer & 84 & $46.9 \%$ \\
\hline & Associate professor & 45 & $25.1 \%$ \\
\hline & Professor & 18 & $10.1 \%$ \\
\hline & Others & 9 & $5.0 \%$ \\
\hline \multirow[t]{4}{*}{ Highest education } & $\begin{array}{l}\text { Junior college and } \\
\text { below }\end{array}$ & 9 & $5.0 \%$ \\
\hline & Undergraduate & 31 & $17.3 \%$ \\
\hline & Master & 107 & $59.8 \%$ \\
\hline & Doctor & 32 & $17.9 \%$ \\
\hline
\end{tabular}

The quality culture could contribute to increase quality awareness, conduct self-assessment, clear quality assurance responsibility and solve quality problems. Quality culture pays attention to quality assurance system, quality management method and quality improvement mechanism as well as quality commitment, participation and capability. The quality culture is embedded into the organizational context and the organizational cultures.( Ehlers, U.D, 2009) So the qualitative and quantitative content are both involved in quality culture, the former is expressed by quality consensus among university members, the latter is expressed by quality index formulation, and the generation performance could reflect th quality culture construction overall situation. The number from 1 to 5 stands for inconformity to conformity, increasing in degree. Answers to above three questions from teachers in different positions are as shown in Table2, Table3 and Table 4.

Table 2 Teachers consensus * Teacher duties Cross tabulation

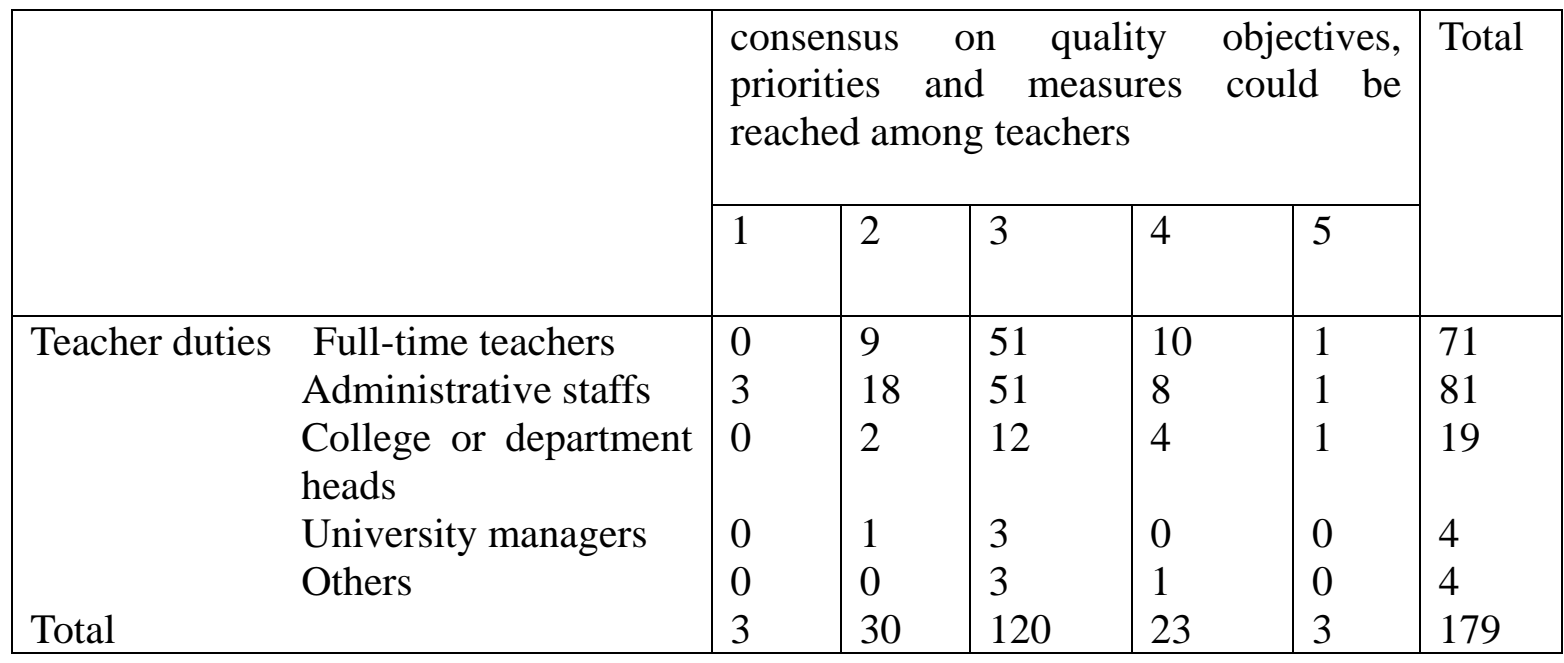


Table 3 Quality index formulation * Teacher duties Cross tabulation

\begin{tabular}{|c|c|c|c|c|c|c|c|}
\hline & \multicolumn{5}{|c|}{$\begin{array}{l}\text { A series of indicators to guarantee } \\
\text { quality culture construction has been } \\
\text { formed in university }\end{array}$} & \multirow[t]{2}{*}{ Total } \\
\hline & & 1 & 2 & 3 & 4 & 5 & \\
\hline \multirow[t]{5}{*}{ Teacher duties } & Full-time teachers & 0 & 8 & 42 & 19 & 2 & 71 \\
\hline & Administrative staffs & 4 & 6 & 44 & 18 & 9 & 81 \\
\hline & $\begin{array}{l}\text { College or department } \\
\text { heads }\end{array}$ & 0 & 2 & 11 & 4 & 2 & 19 \\
\hline & University managers & 2 & 0 & 0 & 2 & 0 & 4 \\
\hline & Others & 0 & 0 & 1 & 2 & 1 & 4 \\
\hline Total & & 6 & 16 & 98 & 45 & 14 & 179 \\
\hline
\end{tabular}

Table 4 Quality culture generation performance * Teacher duties Cross tabulation

\begin{tabular}{|c|c|c|c|c|c|c|c|}
\hline & \multicolumn{5}{|c|}{$\begin{array}{l}\text { Remarkable results have been made in } \\
\text { quality culture construction }\end{array}$} & \multirow[t]{2}{*}{ Total } \\
\hline & & 1 & 2 & 3 & 4 & 5 & \\
\hline \multirow[t]{5}{*}{ Teacher duties } & Full-time teachers & 2 & 11 & 46 & 11 & 1 & 71 \\
\hline & Administrative staffs & 5 & 15 & 53 & 7 & 1 & 81 \\
\hline & $\begin{array}{l}\text { College or department } \\
\text { heads }\end{array}$ & 1 & 3 & 12 & 3 & 0 & 19 \\
\hline & University managers & 1 & 0 & 1 & 2 & 0 & 4 \\
\hline & Others & 0 & 1 & 2 & 1 & 0 & 4 \\
\hline Total & & 9 & 30 & 114 & 24 & 2 & 179 \\
\hline
\end{tabular}

In the three tables above, Table 3 shows that the quality index formulation has the highest approval degree, the application-oriented universities have laid a relatively solid foundation in quantitative system of quality culture construction. University members also could reach a consensus on development goals, general directions and key areas as shown in Table 2 , the qualitative dimension of quality culture construction also have certain guarantee. While the quality culture performance is relatively weak and needs to be further strengthened as shown in Table 4.

\section{Factors Influencing the Performance of Quality Culture in Application-oriented University}

The performance of quality culture in application-oriented universities is well influenced by many factors, the study selected 12 indicators as arguments.(1)Scientific formulation of quality policy, quality planning and conception in application-oriented universities should show characterization, localization and practicability.(2) Effective implementation of quality planning, the implementation of reasonable layout and key support should be reflected in specialty structure adjustment, curriculum content construction, practice teaching reform and teaching team innovation.(3) Effective supervision of quality activities, scale, structure, level and guarantee conditions should be supervised by universities.(4) Appropriateness of quality evaluation content, such as number and proportion of practice courses, practice bases and training centers in teaching, the amount, proportion and funds of applied projects in research, integration between universities and region in social service.(5)Diversity of quality evaluation methods, many evaluation methods should be combined in practice.(6)Feedback of quality evaluation data, relying on assessment information, universities are able to recognize, reflect and solve problems more effectively.(7) Organic integration of quality data, quality data shall be adequately collected and properly classified.(8) Full use of quality data, according to the information data, the university should make clear the advantages and problems of quality assurance, put forward suggestions for improvement and solutions, and then implement the measures.(9) Reasonable disclosure of quality data, quality information disclosure will help application-oriented universities meet the stakeholder demands and 
enhance the social credibility.(10) Wide participation of stakeholders, stakeholders on and off campus should both have the opportunity to participate in quality culture construction.(11) Active participation of stakeholders, participants' initiative and enthusiasm are also important factors.(12) Depth participation of stakeholders, application-oriented universities should have a more open and tolerant attitude to strengthen deep cooperation with all stakeholders. The 12 factors jointly promote the construction of quality culture in application-oriented Universities. Factor analysis of the above 12 items could explore their impact influence and importance. Tests results for KMO and Bartlett are shown in Table 5.

Table 5 KMO and Bartlett's Test

\begin{tabular}{|ll|l|}
\hline Kaiser-Meyer-Olkin Measure of Sampling Adequacy & .934 \\
Bartlett's Test of Sphericity $\quad$ Approx. Chi-Square & 2073.038 \\
& df & 66 \\
Sig. & .000 \\
\hline
\end{tabular}

The bigger the KMO value, the more suitable for factor analysis. When the KMO value is less than 0.5, the data will be not suitable for factor analysis. In Fig. 5, KMO value is 0.934 and significance probability in Bartlett's test of sphere city is 0.000 , less than $1 \%$. So the statistical data is fit for factor analysis. The principle component analysis was used to extract factors. Load factors was obtained through the orthogonal rotation of maximum variance method. According to the standard of factor greater than 0.5, 4 common factor are extracted. The results are shown in Table 6.

Table 6 Rotation Component Matrix of 12 Influence Factors

\begin{tabular}{|l|l|c|c|c|c|}
\hline \multirow{3}{*}{ Factor } & Influence factors of quality culture generation & \multicolumn{4}{|c|}{ Component } \\
\cline { 2 - 6 } & performance & 1 & 2 & 3 & 4 \\
\hline \multirow{4}{*}{ F1 } & Full use of quality data & 0.783 & 0.383 & 0.283 & 0.226 \\
\cline { 2 - 6 } & Reasonable disclosure of quality data & 0.696 & 0.299 & 0.344 & 0.358 \\
\cline { 2 - 6 } & Organic integration of quality data & 0.674 & 0.341 & 0.412 & 0.312 \\
\cline { 2 - 6 } & Feedback of quality evaluation data & 0.618 & 0.342 & 0.289 & 0.434 \\
\hline \multirow{4}{*}{ F2 } & Scientific formulation of quality policy & 0.233 & 0.807 & 0.342 & 0.228 \\
\cline { 2 - 6 } & Effective implementation of quality planning & 0.373 & 0.755 & 0.348 & 0.245 \\
\cline { 2 - 6 } & Effective supervision of quality activities & 0.458 & 0.735 & 0.176 & 0.280 \\
\hline \multirow{3}{*}{ F4 } & Active participation of stakeholders & 0.240 & 0.230 & 0.846 & 0.263 \\
\cline { 2 - 6 } & Depth participation of stakeholders & 0.304 & 0.292 & 0.720 & 0.377 \\
\cline { 2 - 6 } & Wide participation of stakeholders & 0.403 & 0.371 & 0.695 & 0.173 \\
\cline { 2 - 6 } & Appropriateness of quality evaluation content & 0.292 & 0.217 & 0.272 & 0.825 \\
\cline { 2 - 6 } & Diversity of quality evaluation methods & 0.340 & 0.347 & 0.339 & 0.685 \\
\hline
\end{tabular}

In Figure 6, 12 items were merged into 4 common factors. F1 contains 4 arguments, full use of quality data, reasonable disclosure of quality data, organic integration of quality data and feedback of quality evaluation data, relating to data collection, analysis and use, and could be summed up as quality data construction. F2 contains 3 arguments, scientific formulation of quality policy, effective implementation of quality planning and effective supervision of quality activities, and could be summed up as quality strategy management. F3 contains 3 arguments, active participation of stakeholders, depth participation of stakeholders and wide participation of stakeholders, relating to Communication, interaction and cooperation among stakeholders, and could be summed up as stakeholder participation. F4 contains 2 arguments, appropriateness of quality evaluation content and diversity of quality evaluation methods, and could be summed up as quality evaluation mechanism. 


\section{The Generative Path of Quality Culture Construction Performance in Application-oriented Universities}

The 4 common factors containing quality data construction, quality strategy management, stakeholder participation and quality evaluation mechanism, could be examined their influences by regression analysis.

Table 7 Anova $^{\mathrm{b}}$

\begin{tabular}{|c|c|c|c|c|c|c|}
\hline \multicolumn{2}{|c|}{ Model } & Sum of Squares & df & Mean Square & F & Sig. \\
\hline \multirow{2}{*}{1} & Regression & 28.757 & 4 & 7.189 & 18.668 & $.000^{\text {a }}$ \\
\cline { 2 - 8 } & Residual & 67.008 & 174 & .385 & & \\
\cline { 2 - 8 } & Total & 95.765 & 178 & & & \\
\hline
\end{tabular}

a. Predictors: (Constant), quality data construction, quality evaluation mechanism quality strategy management, stakeholder participation, quality evaluation mechanism

b. Dependent Variable, Remarkable achievements in construction of quality culture

Table 8 Coefficients ${ }^{\text {a }}$

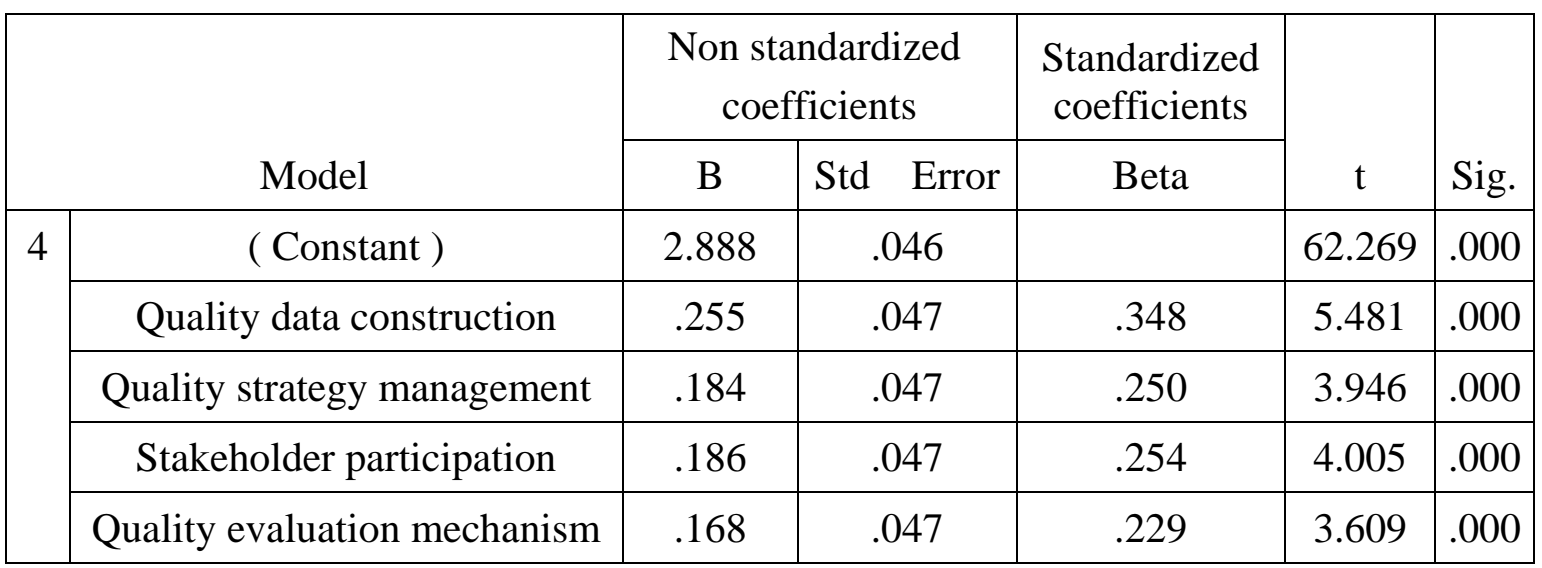

a. Dependent Variable, Remarkable achievements in construction of quality culture

In Table $7, \mathrm{~F}$ is equal to 18.668 , and $\mathrm{P}$ is 0.000 , reaches a very significant level and the regression results are satisfactory. In Table 8, the Significance probabilities of 4 common factors are all 0.000 , less than 0.01 .The 4 factors all play positive roles in quality culture construction in application-oriented universities. The higher beta coefficient means the greater influence.

\section{Summary}

In the post massification stage, only constantly improve the quality application-oriented universities could make a contribution. Quality culture construction is the activity of whole staff and whole process. Specifically, in respect of quality data construction, data integration, utilization, feedback and public should be more service orientation. Quality strategy management should take both internal and external environment into consideration, the former such as quality values, disposable resources and cultural traditions in universities, the latter such as higher education policy and regional industry distribution. In respect of stakeholder participation, universities should seek cooperation in many ways, especially industry partners. Quality evaluation mechanism should show practical, the number of applied courses, the proportion of practice teaching and the amount of popular science activities are all important indicators. The four mechanisms interact with each other to help the application-oriented universities improve their quality culture. 


\section{References}

[1] Wei ZHANG. The Ministry of Education Issued Its First Higher Education Quality Report[EB/OL]. http:// news.xinhuanet.com/legal/2016-04/08/ c_128874181.htm. 2016.4.8. (In Chinese)

[2] Mao-Xun HE. Outline of Quality Culture in Colleges and Universities[J]. Higher Education Forum2004(3):140. (In Chinese)

[3] European University Association. Developing an Internal Quality Culture in European Universities: Report on the Quality Culture Project 2002-2003[R]. Brussels: European University Association, 2005:18.

[4] Ehlers,U.D. Understanding Quality Culture[J]. Quality Assurance in Education,2009(Vol. 17, No. 4):353. 